\title{
ФИЛОСОФИЯ
}

DOI: https://doi.org/10.15688/lp.jvolsu.2017.2.1

UDC 141:319:8

LBC 87.5

\section{PHILOSOPHICAL FOUNDATIONS OF POSTMODERN UNDERSTANDING OF THE MAN}

\author{
Sergey A. Pigalev \\ Volgograd State Social and Pedagogical University, Volgograd, Russian Federation
}

\begin{abstract}
In the article specific features of understanding of the man in the context of postmodern philosophy are investigated. The anthropological sense of such concepts, key for postmodernism, as "text", "rhizome", "the death of the subject", "decentration", "schizoanalysis", etc. comes to light. The hypothesis that a semantic core of postmodern anthropology is the idea of the absolute freedom which is expressed in characteristic negativism in relation to any constraining culture mechanisms is made as a result. In other words, release of suppressed Abnormal regardless of sociocultural correctness of his suppression comes under the spotlight of postmodernism.

Identification of the philosophical bases of postmodern understanding of the man is carried out by means of comparison with the new European anthropological ideal. Taking into consideration the ideas of the German philosopher H. Blyumenberg it is proved that the basic conflict between private will and its comprehensive macrostructures is an inevitable consequence of individualistic anthropology of Modern times. It makes the problem of ensuring sociocultural integrity the central problem of a modernist style. Thus, it is shown that the postmodern anthropology not just denies a modernist style but it is continuation and development of his fundamental contradictions, first of all, contradictions between a part and the whole.
\end{abstract}

Key words: modernist style, nihilism, postmodernism, death of the subject, social development, the man, schizoanalysis.

УДК 141:319:8

ББК 87.5

\section{ФИЛОСОФСКИЕ ОСНОВАНИЯ ПОСТМОДЕРНИСТСКОГО ПОНИМАНИЯ ЧЕЛОВЕКА}

\section{Сергей Александрович Пигалев}

Волгоградский государственный социально-педагогический университет, г. Волгоград, Российская Федерация

\footnotetext{
Аннотация. В статье исследуются специфические особенности понимания человека в контексте постмодернистской философии. Выявляется антропологический смысл таких ключевых для постмодернизма понятий, как «текст», «ризома», «смерть субъекта», «децентрация», «шизоанализ» и т. д. В результате выдвигается гипотеза о том, что смысловым стержнем постмодернистской антропологии является идея абсолютной свободы, выражающаяся в характерном негативизме по отношению к любым сдерживающим механизмам культуры. Другими словами, в центре внимания постмодернизма оказывается высвобождение подавленного Аномального - вне зависимости от социокультурной оправданности его подавления.
} 
Выявление философских оснований постмодернистского понимания человека осуществляется с помощью сравнения с новоевропейским антропологическим идеалом. С опорой на идеи немецкого философа Х. Блюменберга доказывается, что неизбежным следствием индивидуалистической антропологии Нового времени является принципиальный конфликт между частной волей и объемлющими ее макроструктурами. Это делает центральной проблемой модерна проблему обеспечения социокультурной целостности, которая, по-видимому, так и не была решена. Таким образом демонстрируется, что антропология постмодерна не только и не столько отрицает модерн, сколько является продолжением и развитием его фундаментальных противоречий, прежде всего противоречий между частью и целым.

Ключевые слова: модерн, нигилизм, постмодернизм, смерть субъекта, социальное развитие, человек, шизоанализ.

За последние несколько десятилетий в философский лексикон очень прочно вошли разнообразные термины с приставкой «пост». Прожив в течение нескольких веков в пределах социокультурного проекта модерна, западное общество внезапно обнаружило у себя на пороге нежданного «гостя» - эпоху постмодерна. Подобно инфернальному ворону из одноименного стихотворения Э.А. По, постмодерн высказал свое никогда по отношению к фундаментальным константам новоевропейского социокультурного проекта: разуму, истории и, разумеется, человеку.

При этом, если в пределах западной интеллектуальной традиции постмодерн, за некоторыми исключениями (см., например: [22]), укрепился практически без боя, то в контексте отечественной философии ситуация не такая однозначная. В то время как некоторые исследователи принимают постмодернистские метаморфозы [17], другие относятся к ним резко отрицательно [13]. Третьи же, критикуя отдельные составляющие постмодернистского дискурса, открыто заявляют об использовании постмодернистских технологий для утверждения некой своей «истины» [9].

Данное замешательство в какой-то степени подлерживается самими философами-постмодернистами, чьи тексты, будучи главными проводниками духа эпохи, являются, по их собственным заверениям, принципиально асистемными, противоречивыми, чрезмерно литературными и потому ускользающими от всех попыток научной рационализации. Представляется, однако, что на деле ситуация сложнее, чем это кажется на первый взгляд.

Взглянув на ключевые тексты соответствующих авторов, мы можем обнаружить, что в их основании лежит своеобразная концепция человека. Оставляя за собой право на дальнейшие уточнения, дополним эту гипотезу еще одним тезисом: метафизика постмодерна - это метафизика радикального освобождения человека. Речь идет о предельном освобождении от всяческих границ, что на уровне социальной практики предполагает демонтаж всех «сковывающих» механизмов социокультурной и иной интеграции.

Для того чтобы выявить основные аспекты антропологической концепции постмодернизма, обнаружив впоследствии ее возможные основания, есть смысл реконструировать наиболее важные смысловые фрагменты постмодернистской логики. Особое значение при этом имеет по-разному формулируемое, но в принципе разделяемое всеми постмодернистами убеждение, согласно которому «внетекстовой реальности не существует» [8, с. 313]. Это убеждение, в данной формулировке принадлежащее Ж. Деррида, предполагает, что реальность, так же как и истина, - это своего рода иллюзия, за которой скрывается текст, то есть совокупность знаков, символов и множества равноценных, взаимозаменяемых смыслов.

Соответственно, классическое понимание человека в качестве существа, обладающего определенной природой, то есть укорененного в реальности, оказывается бессмысленным. Вырисовывающийся в результате образ «постчеловека» предстает в качестве подвижного, неустойчивого смыслового «сгустка» в пределах текста (то есть культуры), существующего наряду со множеством других таких же «сгустков».

Иными словами, акцент переносится с сущностей на отношения - именно об этом, в частности, говорит знаменитая метафора ризомы (см., например: [7, с. 30]). В результате возникает важнейшая для постмодернизма 
концепция «смерти субъекта», которая выражается в «отказе от артикуляции субъекта, в тотальной деперсонификации действия» [19, c. 51]. В связи с этим некоторые утверждают, что главным мотивом развиваемой постмодернистами логики является критика пресловутого новоевропейского антропоцентризма - в пределах выстраиваемой ими модели «человек перестает быть значимым элементом мира» $[1$, с. 200].

В каком-то смысле это действительно так. В частности, Ж. Делез и Ф. Гваттари начинают свой культовый труд «Капитализм и шизофрения〉 с построения довольно специфической антропологии, в соответствии с которой человек предстает в качестве «желающей машиныл». Желание здесь - отнюдь не свойство личности, а таинственная, разлитая в обществе субстанция, не локализованная в каком-либо определенном месте; потоки желания, тем не менее, образуют некие сгустки, узловые точки, составляющие аморфное единство желающих машин [6, c. 22]. Однако далее Делез и Гваттари подчеркивают, что как только желающие машины образуют некое единство («тело»), это единство в определенный момент начинает жить своей жизнью. Где-то возникает некий центр, который стремится подавить все прочие участки («органы») и прийти в состояние «тела без органов». Так возникает феномен власти или, шире, насилия.

Тема насилия становится доминирующей в постмодернистских текстах, а главным элементом постмодернистского мировосприятия оказывается стремление разоблачать различные механизмы осуществления власти (как известно, «власть повсюду» [21, с. 193]). Иными словами, парадоксальным образом эпоха постмодерна оказывается в гораздо большей степени антропоцентричной, нежели другие эпохи. Порождаемый ею постчеловек в первую очередь сосредоточен на себе и своей специфической свободе, поскольку никаких иных сфер после постмодернистских манипуляций с культурой не остается.

Эти манипуляции представлены такими процедурами, как «децентрация», «деконструкция» и «шизоанализ». Суть их заключается в выявлении и последующем разрушении всех механизмов культуры, которые выполня- ют функции социокультурных интеграторов, осуществляя тем самым отождествление нетождественного. Главными объектами критики при этом являются основные концепты эпохи модерна: «метафизика», «разум», «история», «прогресс», «гуманизм» и, разумеется, «человек». Философскому демонтажу последнего уделяется особое внимание. По мнению P.М. Алейника, постмодернисты видят свою задачу в том, чтобы создать новую модель человека, которая «вбирала бы в себя сферу телесно-физиологическую, сознательного и бессознательного» [1, с. 200], подчеркивая при этом, что человек - «это множественное “Я”, что он есть все вместе взятое, но что его важнейшие ипостаси следует деиерархизировать» [1, с. 200].

Данную стратегию лучше всего выражают Ж. Делез и Ф. Гваттари, противопоставляя два человеческих типа: «невротика» и «шизофреника». В то время как невроз в их интерпретации предстает как проявление «центризма», шизофрения предполагает свободу от соответствующих ограничений. Состояние шизофрении - это состояние тотального отрицания всякой структурности и целостности, в том числе - целостности сознания, ориентированного на определенную иерархию целей.

Соответственно, освобождение от гнета деспотического центра требует шизоанализа. Читаем: «Разрушать, разрушать - работа шизоанализа связана с разрушением $<\ldots$..>. Разрушить <...> иллюзию Эго, марионетку супер-Эго, вину, закон» [6, с. 489]. Другими словами, речь идет о сознательном отказе от субъектности - в том числе исторической. В мире постмодернистской усталости не оказывается места Истории - как сфеpe, в которой возникают, развиваются и взаимодействуют так называемые «большие» смыслы. Как подчеркивает в этой связи Ж. Деррида, «не надо доверять метафизическому концепту истории как истории смысла, который зарождается, развивается, осуществляется» [8, с. 139].

Сама идея Истории как процесса, наполненного смыслом, в данной интерпретации выступает как сугубо искусственная и насильно навязанная идеологема, порожденная потребностями модерна. Подчеркивая факт его 
неизбежного завершения, постмодернисты одновременно настаивают на том, что уходит в прошлое и поддерживаемая им «монопроектность». Разрушение модерна предполагает отмену единого пространства культуры в пользу множества мелких «сфер», не сводимых друг к другу (см., например: [15]).

При переводе в антропологическую плоскость данная логика подразумевает торжество игрового начала в поведении человека. Окружающие его смыслы утрачивают свою структурирующую, побуждающую и мотивирующую силу, превращаясь в своего рода равноценные «кубики», из которых можно в произвольном порядке строить самые разные конструкции забавы ради. «Единственная позитивность, принимаемая в современную эпо$\mathrm{xy},-$ увеличение количества языков, логик, различных сил воздействия. Поли-лог: плюрализация рациональности как ответ на кризис западного разума», - конкретизирует эту ситуацию Ю. Кристева [28, p. 270].

В связи с этим особое значение в постмодернизме приобретает идея аномального. Очевидно, что любая культура осуществляет своего рода разметку реальности, проводя определенные границы между допустимым и недопустимым, то есть аномальным. Подобная разметка, в частности, является одним из факторов, задающих структуру идентичности. Тем не менее аномальное, будучи вытесненным, оказывается максимально свободным от механизмов воздействия власти. В связи с этим неудивительно, что маргинальность, то есть нахождение непосредственно на границе, а то и вовсе за ее пределами, обладает особым очарованием для постмодернистов.

Подразумевается, что нахождение на границе релятивизирует саму идею этой границы, в пределе полностью уничтожая ее. «Фактически, самость - это только порог, дверь, становление между двумя множествами. Каждое множество определяется границей, функционирующей как Аномальное» [7, c. 413], - говорят в этой связи Ж. Делез и Ф. Гваттари. И далее: «Никто более ничего не может сделать для меня или против меня. Мои территории - вне захвата, $<\ldots>>$ потому что я сам собираюсь их расчерчивать» $[7$, c. 397]. В конечном счете речь идет о высво- бождении Аномального как такового, вне зависимости от причин и оправданности его подавления. Это освобождение ради самого освобождения, и в этом смысле оно мало чем отличается от оргии (не случайно одна из глав в работе Ж. Бодрийяра «Прозрачность зла» называется «После оргии» [2]).

Таковы основные черты постмодернистской концепции человека. Тем не менее простое их выявление хоть и необходимо, но все же категорически недостаточно для ответа на более важный вопрос: каково подлинное значение этой концепции в контексте современной культуры? Обсуждение этого вопроса с неизбежностью вскрывает ряд смежных проблем.

Самая главная из них - это проблема $о c$ нований: какие процессы обусловили появление и последующее развитие соответствующих антропологических представлений? Анализ указанной проблематики требует расширения контекста, то есть герменевтической работы с материалом, выходящим за узко антропологические рамки. Прежде всего здесь с неизбежностью всплывает тема модерна.

Принято считать, что постмодернизм в целом и постмодернистская концепция человека в частности представляют собой, в первую очередь, реакцию на закономерный и неизбежный кризис новоевропейского социокультурного проекта. В соответствии с данной логикой модерн и постмодерн предстают как более или менее антагонистические феномены. По этой причине не будет большим преувеличением сказать, что ответ на вопрос об основаниях постмодернистского понимания человека связан с вопросом об отношениях модерна и постмодерна.

Для понимания специфики модерна определенным эвристическим потенциалом обладают идеи немецкого исследователя Х. Блюменберга (см. подробнее: [25]). Анализируя феномен Нового времени, он усматривает его сущность в наличии фундаментальных противоречий, в первую очередь - между частью и целым. Тем не менее, в отличие от многих других, Блюменберг уверен, что эта и другие характерные особенности модерна выходят далеко за пределы Просвещения и даже Возрождения, впервые проявляя себя в период позднего Средневековья. 
Истоком всех проблем, согласно развиваемой логике, выступает известный конфликт между реализмом и номинализмом, закончившийся фактической победой номинализма. Данный конфликт, полагает Блюменберг, значительно шире богословских рамок. Как известно, реализм отстаивал тезис о том, что универсалии (общие понятия) существуют объективно. По сути, это означало, что мир это порождение и воплощение божественного разума. При этом человек, будучи разумным существом, которое создано по образу и подобию божьему, находится на вершине этого воплощения, являясь высшей формой проявления божественной воли.

В свою очередь номинализм, отрицавший объективное существование универсалий, настаивал на существовании только единичных вещей. В этом смысле он, по мнению Блюменберга, подрывал идею о единой природе творения и Творца. Вследствие этого последний преображался в сокрытого Бога, недоступного разуму и открывающегося лишь в мистическом опыте (deus absconditus). Coответственно мир единичных вещей лишался основания, оказываясь предоставленным самому себе.

Равным образом и человек, лишившись божественного «фундамента», став единичной вещью среди других единичных вещей, вынужден самостоятельно раз за разом определять самого себя, изобретать заново в зависимости от ситуации - это, по сути, и означает быть современным (modern). Именно эти процессы в итоге нашли свое отражение в духе модерна, и именно поэтому одной из центральных проблем новоевропейской философии становится поиск модели единства, то есть попытка согласовать динамичное множество отдельных вещей (среди которых и сам человек) с неким константным ядром.

Проблема в том, что в данных обстоятельствах подобное согласование могло восприниматься только как в той или иной мере насильственное. Дело в том, что из всех антропологических теорий Нового времени наибольшее влияние приобретает описание человека в качестве homo economicus - эгоистичного индивидуалиста, озабоченного обеспечением собственного благосостояния. В итоге одним из основных мотивов западной культу- ры становится напряженность между частной волей и подавляющей ее макроструктурой. Ярчайший пример в этом смысле - теория государства-левиафана Т. Гоббса [5].

Более элегантным способом идеологического обоснования модели единства была идея социального развития - правда, в специфической новоевропейской интерпретации. В контексте этой интерпретации выяснялось, что несовершенная, эгоистичная, разрушительная природа homo economicus вовсе не является проблемой, требующей разрешения. Напротив, именно индивидуальное несовершенство, упорядоченное естественными законами, является залогом получения социального блага. Данную идею в разных формах можно обнаружить у самых разных новоевропейских исследователей: Б. Мандевиля [15], А. Смита [20], И. Канта [10] и Г.В.Ф. Гегеля с его концепцией «хитрости разума» [3, с. 84]. Таким образом, примиряя индивидуальный произвол человека-атома с исторической необходимостью в виде естественных законов, идея социального развития представляла собой попытку решить противоречие между частью и целым.

Как бы то ни было, модерн формирует достаточно напряженную среду, причем последняя выступает одновременно и как угроза целостности, и как источник развития. В ситуации, когда внутренние средства для объединения отсутствуют, единственным способом смягчения напряженности становится ее перенаправление вовне: либо против других немодернистских обществ, либо против традиционных сегментов внутри самого модерна. Последний, следовательно, может развиваться только экстенсивно, подвергая отрицанию все прочие социокультурные формы.

Показательно, что разрушительный негативистский импульс модерна признают многие исследователи, начиная с его известного апологета Ю. Хабермаса [22] и заканчивая отечественным исследователем В.А. Кутыревым. Последний, в частности, говорит о присущей новоевропейскому сознанию «неомании», согласно которой «любые сложившиеся системы существуют для того, чтобы, не успев изжить себя органически, скорее исчезнуть и замениться иными, новыми» [12, с. 22]. В свою очередь, венгерская исследователь- 
ница А. Хеллер описывает сущность модерна еще более радикально, подчеркивая, что он вовсе не имеет основы, так как возник через деконструкцию и разрушение всех оснований [27, p. 1].

В связи с этим нельзя не упомянуть про рассуждения известного русско-французского философа А. Кожева. Интерпретируя Гегеля (а это одна из ключевых фигур модерна), последний строит антропологию, согласно которой основными проявлениями человеческой природы становятся желание («жажда признания») и отрицание всего того, что мешает реализоваться этому желанию. В итоге Кожев очень емко описывает человека как ничто, «это ничто - ничтожествующее в бытии» [11, с. 110].

Значение фигуры Кожева и его идей сложно переоценить. Известно, что его лекции, читавшиеся в 30-е гг. в Высшей практической школе во Франции, на которых присутствовал будущий авангард французской мысли, имели большой успех. Как отмечает В. Россман, «после лекций Кожева французская литература заселяется новыми героями, людьми-ничто, лиминального опыта, немотивированной негативности» [18].

С данной точки зрения отношения между модерном и постмодерном предстают в новом свете: последний видится не столько как чистое отрицание первого, сколько как развитие его собственных негативистских и нигилистических тенденций. Это обстоятельство станет еще более очевидным, если вспомнить о таком феномене, как ницшеанство. Ф. Ницше, будучи, по всеобщему признанию, одним из вдохновителей постмодернизма, является также одним из первых, кто наиболее детально описал и проанализировал феномен нигилизма.

«Что обозначает нигилизм? To, что высиие иенности теряют свою иенность. Нет цели. Нет ответа на вопрос “зачем"?» [16, c. 36] - писал он. В эпоху нигилизма более ничто не способно мотивировать, направить или организовать человечество - точнее, только ничто на это и способно: как известно, в центре ницшеанских рассуждений лежит простой и пугающий тезис о том, что человеческим поведением на самом деле руководит «воля к власти» - хтоническая энергия, порожденная самой жизнью.
По-настоящему, однако, важно другое: полвека спустя М. Хайдеггер, философ не менее выдающийся, анализируя ницшеанскую идею нигилизма, подчеркивал, что это «всемирно-историческое движение тех народов Земли, которые вовлечены в сферу влияния Нового времени» [23, с. 148]. С его точки зрения, именно нигилизм является неочевидным внутренним стержнем всей новоевропейской метафизики, идеи же Ницше - это наивысшая точка ее развития: они выводят на поверхность то, что раньше было скрыто.

Представляется, что выход негативистской сущности модерна за пределы установленных им же границ связан, в числе всего прочего, с метаморфозами идеи социального развития. К началу $\mathrm{XX}$ в. эта идея, являясь, как утверждалось выше, философским фундаментом для построения новоевропейской модели единства, начинает проявлять признаки кризиса. С нашей точки зрения, в разворачивающемся процессе можно выделить два основных аспекта.

Первый аспект связан со все более очевидным исчерпанием исторических энергий новоевропейского общества. В описываемый период динамика модерна приобретает по большей части инерционный характер, поскольку значительная часть возможных пространств оказывается уже захваченной - либо в прямом смысле, либо в мировоззренческом. Это так, поскольку модель социального развития, предложенная модерном, изначально предполагает наличие некоторого внешнего Другого, который должен быть подвергнут «отрицанию», то есть преобразован, модернизирован.

В условиях отсутствия этого Другого модерн теряет свой основной импульс к развитию. Фактически первые признаки этого состояния зафиксировал Г.В.Ф. Гегель, вскользь и пока еще в оптимистичном ключе упоминая о наступлении «конца истории» [3]. Уже в XX в. в связи с развитием глобализационных процессов ситуация становится более острой, порождая целую плеяду тревожных текстов, описывающих состояние исторической растерянности. Особенно известен в этом отношении А. Гелен, рассуждавший о «культурной кристаллизации», под которой он понимал стагнацию социкультурного развития (см.: [26]). 
Второй аспект кризиса новоевропейской идеи социального развития связан с нарастающей катастрофичностью мировой истории. Вера в социальное благо, порождаемое несовершенной эгоистичной природой homo economicus, могла, по-видимому, существовать и поддерживаться только в условиях относительной безболезненности исторического процесса. В атмосфере богатого на войны и революции XX в. эта вера существенно слабеет. Европейское стремление «делать историю» стремительно истощается, а сама историческая стихия начинает восприниматься со специфической брезгливостью. Как пишет в связи с этим К. Ясперс, «мы внезапно ощущаем внезапную неудовлетворенность историей» [24, c. 277].

Оба аспекта кризиса идеи социального развития имеют, однако, один антропологический итог: новоевропейская модель единства перестает работать. В результате атомизированный, негативистски заряженный новоевропейский человек оказывается предоставлен самому себе, а характерная для общества модерна напряженность более не имеет выхода. В подобной ситуации неизбежна переориентация импульса отрицания в сторону системообразующих принципов самого модерна. Таким образом, мы имеем право сказать, что модерн в итоге противоречит самому себе, или, как указывает А. Хеллер, «динамика модерна может прорвать границы модернистского социального устройства и отринуть модерн» [27, p. 2].

Таким образом, есть основания предположить, что, несмотря на демонстративную постмодернистскую расправу с основными константами новоевропейского сознания, различия между модерном и постмодерном далеко не так фундаментальны, как может показаться. С учетом всего сказанного выше постмодернистский нигилизм раскрывает себя как порождение негативизма модерна. Отличие заключается в том, что в постмодернизме этот негативизм доходит до крайности, освобождается от всех конструктивных элементов и обращается как против самого модерна, так и против любой «нормальной» культуры.

При этом показательно, что постмодерн, так же как и модерн в свое время, позициони- руется в качестве безальтернативной «судьбы бытия», а постчеловек явно либо неявно рассматривается как окончательное антропологическое состояние. Проблема, однако, заключается в том, что постчеловек оказывается существом более уязвимым и неустойчивым, нежели любой другой антропологический тип. Будучи неспособным организоваться под эгидой «больших» смыслов, он, тем не менее, с легкостью попадает под действие наскоро слепленных идеологических конструктов, обращающихся не столько к разуму, сколько к бессознательной, инстинктивной сфере. Эти конструкты зачастую порождают эклектичные, аморфные сообщества, которые, выполнив необходимые задачи, моментально распадаются за ненадобностью. Самый очевидный пример этого феномена - все недавние квазиреволюции как в ближнем, так и в дальнем зарубежье.

Саму окончательность постчеловеческого состояния также можно поставить под сомнение. В качестве пояснения есть смысл провести параллель между описываемыми процессами и образами, разрабатываемыми известным немецким писателем Г. Гессе в философско-художественном романе «Степной волк». Главный герой на протяжении всего повествования тяготится постылым буржуазным существованием и пытается освободиться, вырваться за его пределы. Наконец, ему снится сон, в котором его стремление реализуется, причем в предельной форме - он освобождается от своей собственной идентичности. Он видит, как его отражение в зеркале «деконструируется», распадается на части: «От него отделилась вторая фигура, третья, десятая, двадцатая, и все огромное зеркало заполнилось сплошными Гарри или кусками Гарри, бесчисленными Гарри» [4, с. 360].

Однако впоследствии этот сон сменяется другим, в котором герой наблюдает новый мир, свободный от всех сдерживающих механизмов старой реальности. Этот переживший деконструкцию мир оказывается миром, наполненным архаическим, бесцельным, животным разрушением. «Это была война $<\ldots>$, где каждый, кому не хватало воздуха и приелась жизнь, выражал свое недовольство разительным образом» [4, с. 362], пишет Гессе. 
Образы Гессе сами по себе ничего не доказывают, однако нельзя не обратить внимание на сходство между ними и рассуждениями Ж. Делеза и Ф. Гваттари. Последние для пояснения идеи шизоанализа используют характерную метафору «становление животным», подчеркивая то, казалось бы, очевидное обстоятельство, что деконструкция основных человеческих параметров неизбежно предполагает возврат к параметрам дочеловеческим. «Жуткая инволюция зовет нас к неслыханным становлениям» [7, с. 397], - заявляют они.

Любопытно, что подобные настроения находят отражение и в современной массовой культуре, в частности, в недавнем фильме режиссера М.Н. Шьямалана «Сплит» (2016 г.), который рассказывает о человеке, в сознании которого сосуществуют 23 личности, которые в произвольном порядке переключаются. При этом все они находятся в ожидании появления 24-й личности, которая, будучи, по слухам, своего рода сверхчеловеком, носит весьма характерную кличку «Зверь». Иначе говоря, животное и сверхчеловеческое начала совпадают (что заставляет вспомнить еще и Ф. Ницше).

Таким образом, есть основания предположить, что закономерным результатом постмодернистской манипуляции с фундаментальными антропологическими параметрами является соскальзывание постчеловека в архаическое состояние, но - в обновленной, лишенной конструктивных элементов форме. Специфика журнальной статьи, однако, не позволяет в полной мере рассмотреть особенности этого процесса - это тема для будущих исследований. Тем не менее представляется, что сказанного достаточно для того, чтобы вновь поднять вопрос о границах и степени социокультурной продуктивности постмодернистских представлений о человеке.

\section{СПИСОК ЛИТЕРАТУРЫ}

1. Алейник, Р. М. Образ человека во французской постмодернистской литературе / Р. М. Алейник // Спектр антропологических учений. - М. : ИФ PAH, 2006. - C. 199-214.

2. Бодрийяр, Ж. Прозрачность зла / Ж. Бодрийяр. - М. : Добросвет, 2014. - 260 с.
3. Гегель, Г. В. Ф. Философия истории / Г. В. Ф. Гегель. - СПб. : Наука, 1993. - 480 с.

4. Гессе, Г. Степной волк / Г. Гессе // Собр. соч. В 4 т. Т. 2 / Г. Гессе. - СПб. : Северо-запад, 1994. $416 \mathrm{c}$.

5. Гоббс, Т. Левиафан, или материя, форма и власть государства церковного и гражданского / Т. Гоббс // Соч. В 2 т. Т. 2 / Т. Гоббс. - М. : Мысль, 1991. -C. 6-545.

6. Делез, Ж. Анти-Эдип: Капитализм и шизофрения / Ж. Делез, Ф. Гваттари. - Екатеринбург : У-Фактория, 2007. - $672 \mathrm{c}$.

7. Делез, Ж. Тысяча плато: Капитализм и шизофрения / Ж. Делез, Ф. Гваттари. - Екатеринбург : У-Фактория ; М. : Астрель, 2010. - 895 с.

8. Деррида, Ж. О грамматологии / Ж. Деррида. - М. : Ad Marginem, 2000. -511 c.

9. Дугин, А. Г. Постмодерн? / А. Г. Дугин. Электрон. текстовые дан. - Режим доступа: $\mathrm{http} / / /$ www.arcto.ru/modules.php name $=$ News \&file $=$ article \&sid=221 (дата обращения: 12.05.2017). - Загл. с экрана.

10. Кант, И. Идея всеобщей истории во всемирно-гражданском плане / И. Кант // Собр. соч. В 8 т. Т. 8 / И. Кант. - М. : Чоро, 1994. - С. 12-28.

11. Кожев, А. Введение в чтение Гегеля / А. Кожев. - СПб. : Наука, 2003. - 792 с.

12. Кутырев, В. А. Время Mortido / В. А. Кутырев // Вопросы философии. - 2011 - - № 7. - С. 19-28.

13. Кутырев, В. А. Философия постмодернизма / В. А. Кутырев. - Н. Новгород : Изд-во ВолгоВят. акад. гос. службы, 2006. -95 с.

14. Лиотар, Ж.-Ф. Состояние постмодерна / Ж.-Ф. Лиотар. - М. : Ин-т экспериментальной социологии ; СПб. : Алетейя, 1998. - 160 с.

15. Мандевиль, Б. Басня о пчелах / Б. Мандевиль. - М. : Мысль, 1974. - 376 с.

16. Ницше, Ф. Воля к власти: опыт переоценки всех ценностей / Ф. Ницше. - М. : REFL-book, 1994. $352 \mathrm{c}$.

17. Подорога, В. А. Феноменология тела / В. А. Подорога. - М. : Ad Marginem, 1995. - 341 c.

18. Россман, В. После философии: Кожев, «конец истории» и русская мысль / В. Россман. - Электрон. текстовые дан. - Режим доступа: http:// magazines.russ.ru/nz/1999/5/rossman.html (дата обращения: 18.05.2017). - Загл. с экрана.

19. Сербул, А. А. «Смерть субъекта»: философско-культурологический анализ проблемы субъекта в постмодернистском дискурсе / А. А. Сербул // Веснік Палескага дзяржаунага університэта. Серыя грамадских і гуманітарных навук. - 2011. - № 2. C. 51-55.

20. Смит, А. Исследование о природе и причинах богатства народов / А. Смит. - М. : Соцэкгиз, 1962. $-677 \mathrm{c}$. 
21. Фуко, М. Воля к истине. По ту сторону знания, власти и сексуальности / М. Фуко. - М. : Магистериум-Касталь, 1996. - 448 с.

22. Хабермас, Ю. Модерн - незавершенный проект / Ю. Хабермас // Вопросы философии. 1992. - № 4. - С. 40-51.

23. Хайдеггер, М. Слова Ницше «Бог мертв» / М. Хайдеггер // Вопросы философии. - 1990. № 7. - С. 143-176.

24. Ясперс, К. Истоки истории и ее цель / К. Ясперс // Смысл и назначение истории. - М. : Политиздат, 1991. - С. 28-286.

25. Blumenberg, $\mathrm{H}$. The legitimacy of the modern age / H. Blumenberg. - L. : The MIT Press, 1999. XXX, 677 p.

26. Gehlen, A. The crystallization of cultural forms / A. Gehlen // Modern German Sociology. - N. Y. : Columbia University Press, 1987. - P. 218-231.

27. Heller, A. The three logics of modernity and the double bind of the modern imagination / A. Heller. - Budapest : Collegium Budapest Publ., 2000. $-31 \mathrm{p}$.

28. Kristeva, J. Polylogue / J. Kristeva. - P. : Seuil Publ., 1977. -537 p.

\section{REFERENCES}

1. Aleynik R.M. Obraz cheloveka vo frantsuzskoy postmodernistskoy literature [The Image of Man in French Postmodernist Literature]. Spektr antropologicheskikh ucheniy [The Spectrum of Anthropological Studies]. Moscow, IF RAN Publ., 2006, pp. 199-214.

2. Baudrillard J. Prozrachnost zla [The Transparency of Evil]. Moscow, Dobrosvet Publ., 2014. 260 p.

3. Hegel G.V.F. Filosofiya istorii [The Philosophy of History]. Saint Petersburg, Nauka Publ., $1993.480 \mathrm{p}$.

4. Gesse G. Stepnoy volk [Steppe Wolf]. Sobranie sochineniy. V 4 t. T. 2 [Collected Works in 4 vols. Vol. 2]. Saint Petersburg, Severo-zapad Publ., $1994.416 \mathrm{p}$.

5. Gobbs T. Leviafan, ili materiya, forma i vlast gosudarstva tserkovnogo i grazhdanskogo [Leviathan or The Matter, Forme and Power of a Common Wealth Ecclesiasticall and Civil]. Sochineniya. V 2 t. T. 2 [Works in 2 vols. Vol. 2]. Moscow, Mysl Publ., 1991, pp. 6-545.

6. Deleuze G., Gvattari F. Anti-Edip: Kapitalizm $i$ shizofreniya [Anti-Oedipus: Capitalism and Schizophrenia]. Ekaterinburg, U-Faktoriya Publ., 2007. $672 \mathrm{p}$.

7. Deleuze G., Gvattari F. Tysyacha plato: Kapitalizm i shizofreniya [A Thousand Plateaus:
Capitalism and Schizophrenia]. Ekaterinburg, UFaktoriya Publ.; Moscow, Astrel Publ., 2010. 895 p.

8. Derrida G. Ogrammatologii [On Grammatology]. Moscow, Ad Marginem Publ., 2000. 511 p.

9. Dugin A.G. Postmodern? [Postmodernity?].

URL: http://www.arcto.ru/modules.php?name=News\& file $=$ article\&sid=221. (accessed May 12, 2017).

10. Kant I. Ideya vseobshchey istorii vo vsemirno-grazhdanskom plane [The Idea of Universal History on a Cosmopolitical Plan]. Sobranie sochineniy. V8t. T. 8 [Collected Works in 8 vols. Vol. 8]. Moscow, Choro Publ., 1994, pp. 12-28.

11. Kozhev A. Vvedenie v chtenie Gegelya [Introduction to the Reading of Hegel]. Saint Petersburg, Nauka Publ., 2003. 792 p.

12. Kutyrev V.A. Vremya Mortido [The Mortido Time]. Voprosy filosofii, 2011, no. 7, pp. 19-28.

13. Kutyrev V.A. Filosofiya postmodernizma [The Philosophy of Postmodernism]. Nizhny Novgorod, Volgo-Vyat. akad. gos. sluzhby Publ., 2006. 95 p.

14. Liotar Zh.-F. Sostoyanie postmoderna [The Condition of Postmodernity]. Moscow, In-t eksperimentalnoy sotsiologii Publ.; Saint Petersburg, Aleteya Publ., 1998. 160 p.

15. Mandevil B. Basnya o pchelakh [Fable on the Bees]. Moscow, Mysl Publ., 1974. 376 p.

16. Nietzsche F.W. Volya $k$ vlasti: opyt pereotsenki vsekh tsennostey [The Will to Power]. Moscow, REFL-book Publ., 1994. 352 p.

17. Podoroga V.A. Fenomenologiya tela [The Phenomenology of Body]. Moscow, Ad Marginem Publ., 1995. 341 p.

18. Rossman V. Posle filosofii: Kozhev, «konets istorii» i russkaya mysl [After Philosophy: Kozhev, "the End of History" and Russian Thought]. URL: http:// magazines.russ.ru/nz/1999/5/rossman.html. (accessed May 18, 2017).

19. Serbul A.A. «Smert subyekta»: filosofskokulturologicheskiy analiz problemy subyekta $\mathrm{v}$ postmodernistskom diskurse ["The Death of Individual": Philosophical and Culturological Analysis of the Problem of Individual in Postmodernist Discourse]. Vesnik Paleskaga dzyarzhaunaga universiteta. Seryya gramadskikh i gumanitarnykh navuk, 2011, no. 2, pp. 51-55.

20. Smit A. Issledovanie o prirode i prichinakh bogatstva narodov [An Inquiry into the Nature and Causes of the Wealth of Nations]. Moscow, Sotsekgiz Publ., 1962. 677 p.

21. Foucault M. Volya $k$ istine. Po tu storonu znaniya, vlasti i seksualnosti [The Will to Truth. Beyond Knowledge, Power, and Sexuality]. Moscow, Magisterium-Kastal Publ., 1996. 448 p.

22. Habermas Ju. Modern - nezavershennyy proekt [Unfinished Project of Modernity]. Voprosy filosofii, 1992, no. 4, pp. 40-51. 
23. Heidegger M. Slova Nitsshe "Bog mertv» [Nietzsche's Words: “God Is Dead"]. Voprosy filosofii, 1990, no. 7, pp. 143-176.

24. Jaspers K. Istoki istorii i ee tsel [The Origin and Goal of History]. Smysl i naznachenie istorii [The Sense and Objective of History]. Moscow, Politizdat Publ., 1991, pp. 28-286.

25. Blumenberg H. The Legitimacy of the Modern Age. London, The MIT Press, 1999. XXX, 677 p.
26. Gehlen A. The Crystallization of Cultural Forms. Modern German Sociology. New York, Columbia University Press, 1987, pp. 218-231.

27. Heller A. The Three Logics of Modernity and the Double Bind of the Modern Imagination. Budapest, Collegium Budapest Publ., 2000. 31 p.

28. Kristeva J. Polylogue. Paris, Seuil Publ., 1977. $537 \mathrm{p}$.

\section{Information About the Author}

Sergey A. Pigalev, Candidate of Philosophical Sciences, Senior Teacher, Department of Philosophy and Cultural Science, Volgograd State Social and Pedagogical University, Prosp. V.I. Lenina, 27, 400066 Volgograd, Russian Federation, serge1403@mail.ru, culture1@mail.ru.

\section{Информация об авторе}

Сергей Александрович Пигалев, кандидат философских наук, старший преподаватель кафедры философии и культурологии, Волгоградский государственный социально-педагогический университет, просп. им. В.И. Ленина, 27, 400066 г. Волгоград, Российская Федерация, serge1403@mail.ru, culture1@mail.ru. 